\title{
An Anatomical Basis for Opponent Process Mechanisms of Opiate Withdrawal
}

\author{
Anna K. Radke, ${ }^{1}$ Patrick E. Rothwell, ${ }^{1}$ and Jonathan C. Gewirtz ${ }^{1,2,3}$ \\ ${ }^{1}$ Graduate Program in Neuroscience and the Departments of ${ }^{2}$ Neuroscience and ${ }^{3}$ Psychology, University of Minnesota, Minneapolis, Minnesota 55455
}

Opponent process theory predicts that the first step in the induction of drug withdrawal is the activation of reward-related circuitry. Using the acoustic startle reflex as a model of anxiety-like behavior in rats, we show the emergence of a negative affective state during withdrawal after direct infusion of morphine into the ventral tegmental area (VTA), the origin of the mesolimbic dopamine system. Potentiation of startle during withdrawal from systemic morphine exposure requires a decrease in opiate receptor stimulation in the VTA and can be relieved by administration of the dopamine receptor agonist apomorphine. Together, our results suggest that the emergence of anxiety during withdrawal from acute opiate exposure begins with activation of VTA mesolimbic dopamine circuitry, providing a mechanism for the opponent process view of withdrawal.

\section{Introduction}

The "opponent process" theory of motivation suggests that rewarding experiences engage secondary mechanisms that oppose and constrain positive emotion (Solomon and Corbit, 1974). Consistent with this perspective, the initial, rewarding effects of drugs of abuse are followed by the emergence of a negative emotional state each time a drug is experienced, including the first (Koob and Le Moal, 1997; Harris and Gewirtz, 2004; Rothwell et al., 2009). Negative emotional symptoms of withdrawal are therefore an intrinsic component of daily drug exposure and likely contribute to the development of dependence. Although negative affective states are thought to play a primary role in compulsive drug use (Koob and Le Moal, 1997; Baker et al., 2004), the neural mechanisms involved in the development of these states have yet to be elucidated.

The opponent process view predicts that activation of rewardrelated circuitry is the first step in the induction of a negative affective withdrawal state following opiate exposure (Koob and Bloom, 1988; Koob and Le Moal, 1997; Vargas-Perez et al., 2009). Opiates activate the brain's reward circuits through disinhibition of mesolimbic dopaminergic neurons in the ventral tegmental area (VTA) (Johnson and North, 1992). These neurons project to the nucleus accumbens (NAc) as well as other mesolimbic targets, including the basolateral amygdalar complex and the "extended amygdala" (i.e., central nucleus of the amygdala, lateral bed nucleus of the stria terminalis, and shell of the NAc) (Fallon

\footnotetext{
Received Jan. 10, 2011; revised April 11, 2011; accepted April 11, 2011.

Author contributions: A.K.R., P.E.R., and J.C.G. designed research; A.K.R. and P.E.R. performed research; A.K.R. and P.E.R. analyzed data; A.K.R., P.E.R., and J.C.G. wrote the paper.

This work was funded by grants from NICHD (HD007151 to A.K.R.) and NIDA (DA007097 to A.K.R., DA007234 and DA023750 to P.E.R., and DA018784 to J.C.G.). We thank Dr. Mark Thomas for supplying the locomotor activity monitors used in these experiments.

Correspondence should be addressed to Jonathan C. Gewirtz, Department of Psychology, N-218 Elliott Hall, 75 East River Road, Minneapolis, MN 55455. E-mail: jgewirtz@umn.edu.

P.E. Rothwell's present address: Neuroscience Institute, Stanford University, Palo Alto, CA 94304.

DOI:10.1523/JNEUROSCI.0172-11.2011

Copyright $\odot 2011$ the authors $\quad 0270-6474 / 11 / 317533-07 \$ 15.00 / 0$
}

et al., 1978; de Olmos and Heimer, 1999; Hasue and ShammahLagnado, 2002; Meloni et al., 2006). Structures of the extended amygdala are critical for the expression of negative emotional symptoms of opiate withdrawal (Koob and Le Moal, 1997; Frenois et al., 2002; Nakagawa et al., 2005; Harris et al., 2006), and dopamine signaling in these structures is involved in states of fear and anxiety (Herman et al., 1982; Pezze and Feldon, 2004; Meloni et al., 2006). We therefore hypothesized that anxiety during opiate withdrawal occurs in response to changes in activity of the mesolimbic dopamine system.

To test this hypothesis, anxiety-like behavior was assessed in rats using the acoustic startle reflex, a well characterized translational measure of fear and anxiety (Davis et al., 2010). The magnitude of this reflex is reliably increased during withdrawal from acute morphine exposure (i.e., "withdrawal-potentiated startle") (Kalinichev and Holtzman, 2003; Harris and Gewirtz, 2004; Cabral et al., 2009; Rothwell et al., 2009), an effect that involves portions of the extended amygdala (Harris et al., 2006; Cabral et al., 2009) and is attenuated by administration of anxiolytic drugs (Harris and Gewirtz, 2004; Rothwell et al., 2009). The experiments described below provide direct support for the opponent process theory of opiate withdrawal by demonstrating that the actions of morphine in the rodent VTA are both sufficient and necessary to induce anxiety-like behavior during withdrawal from acute opiate exposure.

\section{Materials and Methods \\ Subjects}

Male Sprague Dawley rats (Harlan), weighing between 225 and $375 \mathrm{~g}$ at the start of the experiment, were housed in groups of four in metal cages with a $12 \mathrm{~h} \mathrm{light/dark} \mathrm{cycle} \mathrm{and} \mathrm{free} \mathrm{access} \mathrm{to} \mathrm{food} \mathrm{and} \mathrm{water,} \mathrm{except}$ during testing. Animals were acclimated to housing conditions for 2 weeks and then gently handled for 2 consecutive days. Rats that underwent intracranial cannulation surgery were subsequently housed individually in metal cages. All procedures conformed to the National Institutes of Health Guide for the Care and Use of Laboratory Animals and were approved by the University of Minnesota Institutional Animal Care and Use Committee. 
Drugs

Morphine sulfate was purchased from Mallinckrodt. Apomorphine hydrochloride was purchased from Tocris Bioscience. Naloxone hydrochloride was purchased from Sigma-Aldrich. Systemically administered drugs were dissolved in $0.9 \%$ saline and injected subcutaneously. Infused drugs were dissolved in $0.9 \%$ sterile saline. Throughout the text, $0 \mathrm{mg} / \mathrm{kg}$ and $0 \mu \mathrm{g}$ denote groups given vehicle injection or infusion, respectively. All drug doses are expressed as the weight of the salt.
Table 1. Mean raw startle output for animals in experiment 1

\begin{tabular}{llll}
\hline & $0 \mu \mathrm{g}$ morphine & $1 \mu \mathrm{g}$ morphine & $5 \mu \mathrm{g}$ morphine \\
\hline $2 \mathrm{~h}$ & $49.3 \pm 3.4$ & $47.8 \pm 4.5$ & $45.1 \pm 4.1$ \\
$4 \mathrm{~h}$ & $54.4 \pm 5.5$ & $43.5 \pm 3.8$ & $40.5 \pm 2.8$ \\
$6 \mathrm{~h}$ & $48.6 \pm 3.8$ & $50.1 \pm 4.9$ & $45.0 \pm 4.3$ \\
$8 \mathrm{~h}$ & $47.8 \pm 3.8$ & $47.2 \pm 5.2$ & $39.5 \pm 3.2$ \\
\hline
\end{tabular}

Data are the average startle values of animals before intra-VTA morphine infusion.

\section{Intracranial cannulation and infusion}

Surgical procedures were performed as previously described (Harris et al., 2006). Twentytwo gauge guide cannulae (model C232G-2.0; Plastics One Products) were implanted bilaterally into the VTA (anteroposterior: $-5.3 \mathrm{~mm}$; mediolateral: $\pm 1.0 \mathrm{~mm}$; dorsoventral: $-7.2 \mathrm{~mm}$ from bregma). "Dummy" cannulae (model C232DC; Plastics One Products) were inserted to maintain patency, with the tips flush with the end of the guide cannulae.

Infusions of $0.5 \mu \mathrm{l}$ per hemisphere were made over the course of 2 min through 28 gauge infusion cannulae (model C232I-2.0; Plastics One Products) with tips that extended $1 \mathrm{~mm}$ past the end of the guide. Infusion cannulae were attached with polyethylene tubing to a $5 \mu$ l Hamilton microsyringe and were left in place for $1 \mathrm{~min}$ following infusions.

\section{Acoustic startle}

Acoustic startle was tested as previously described (Rothwell et al., 2009). Each startle test session consisted of a 5 min acclimation period followed by presentation of 40 startle stimuli (20 each at 95 or $105 \mathrm{~dB}$ in semirandom order) with a $30 \mathrm{~s}$ fixed interstimulus interval. For each experiment, acoustic startle was first tested on 2 consecutive drug-free days. After the second day, average startle amplitudes were used to match animals into groups with similar overall mean startle amplitude (Gutman et al., 2008). Each test day began with a pre-drug exposure baseline startle session and concluded with a final post-drug exposure startle session.

\section{Locomotor activity}

Locomotor activity was monitored as previously described (Rothwell et al., 2010). A computer running custom software (Applied Concepts) monitored the number of "crossovers." Crossovers were analyzed in 10 min bins and also were summed across the entire experimental session. One day before drug exposure, animals were habituated to activity boxes for $1 \mathrm{~h}$. On test days, locomotor activity was monitored for $2 \mathrm{~h}$ after infusion.

\section{Experimental design}

Experiment 1: intra-VTA morphine infusion. On each test day, animals were infused with 0,1 , or $5 \mu \mathrm{g}$ morphine sulfate per hemisphere at $0 \mathrm{~h}$. Locomotor activity was monitored for $2 \mathrm{~h}$ immediately after the infusion. Startle was assessed at one of 4 post-morphine infusion time points $(2,4$, 6 , and $8 \mathrm{~h}$ ). A Latin square design was used so that each rat was tested once at each of the four postinfusion time points over a series of $4 \mathrm{~d}$. Rats underwent a total of 4 test days, each separated by 2 intervening days to prevent tissue damage (Vezina and Stewart, 1984). Of the rats implanted with cannulae in the VTA, seven were removed from analysis due to misplaced cannulae [located in the lateral hypothalamus (LH)] or significant lesions at the infusion site, leaving final sample sizes of $17(0 \mu \mathrm{g}), 14$ $(1 \mu \mathrm{g})$, and $14(5 \mu \mathrm{g})$. In a separate control experiment, animals with cannulae located $1 \mathrm{~mm}$ dorsal to the VTA in the interstitial nucleus of the medial longitudinal fasciculus (IMLF) were infused with 0 or $1 \mu \mathrm{g}$ of morphine and tested as described above. Of these animals, 8 were removed from analysis due to misplaced cannulae, leaving final sample sizes of $9(0 \mu \mathrm{g})$ and $7(1 \mu \mathrm{g})$.

Experiment 2: intra-VTA morphine infusion during withdrawal from systemic morphine. Rats were injected with either 0 or $10 \mathrm{mg} / \mathrm{kg}$ morphine at $0 \mathrm{~h}$ and received an intra-VTA infusion of morphine $(0$ or $1 \mu \mathrm{g}$ per side) $3 \mathrm{~h}$ later. Startle was tested at $4 \mathrm{~h}$. A crossover design was used so that each rat was infused with the two doses of intra-VTA morphine in a random order over 2 consecutive test days. One animal was removed from analysis due to problems with the infusion on the second test day and 6 animals were removed due to misplaced cannulae, leaving final sample sizes of $12(0 \mathrm{mg} / \mathrm{kg})$ and $11(10 \mathrm{mg} / \mathrm{kg})$.

Morphine-injected animals in this experiment had previously been tested for intra-VTA methylnaloxonium-precipitated withdrawal (Stinus et al., 1990; Maldonado et al., 1992) following systemic morphine exposure (no significant startle potentiation, data not shown), and had therefore previously received one $10 \mathrm{mg} / \mathrm{kg}$ injection of morphine and two $500 \mathrm{ng}$ intra-VTA infusions of methylnaloxonium. The lack of startle potentiation following methylnaloxonium infusion was likely due to the anxiolytic effects of morphine in brain regions outside of the VTA (Cabral et al., 2009).

Experiment 3: intra-VTA naloxone infusion before intra-VTA morphine. Rats were infused with 0,3 , or $10 \mu$ g of naloxone hydrochloride followed by 0 or $1 \mu \mathrm{g}$ of morphine per side 20 min later. Startle was tested at $4 \mathrm{~h}$. Each rat was infused with the three doses of intra-VTA naloxone in a random order over 3 test days, separated by 2 intervening days. One animal was removed from analysis due to misplaced cannulae, and one was removed as an outlier, leaving final sample sizes of $11(0 \mu \mathrm{g})$ and $8(1 \mu \mathrm{g})$.

Experiment 4: apomorphine injection during withdrawal from systemic morphine. Rats were injected with morphine or saline at $0 \mathrm{~h}$ followed by $0(N=14$ per group $), 50(N=10$ per group $)$, or $100 \mu \mathrm{g} / \mathrm{kg}(N=10$ per group) apomorphine hydrochloride $3 \mathrm{~h}$ and $50 \mathrm{~min}$ later. This higher dose of apomorphine has been shown to cause cellular changes mediated by activation of postsynaptic dopamine receptors (Bergstrom et al., 1982; Carlson et al., 1987; Rosenkranz and Grace, 1999). Startle was tested at $4 \mathrm{~h}$.

\section{Data analysis}

Startle data were collapsed across both intensities (95/105 dB) before further statistical analysis (Harris and Gewirtz, 2004), as the magnitude of withdrawal-potentiated startle was not affected by stimulus intensity 
A

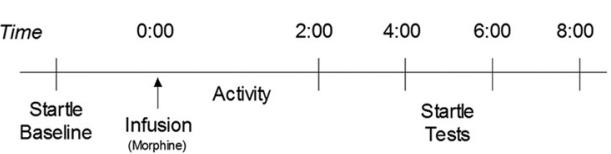

B

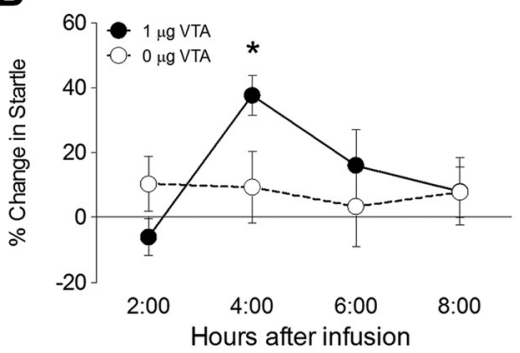

D

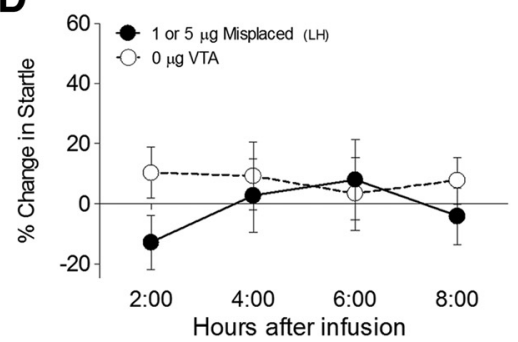

C
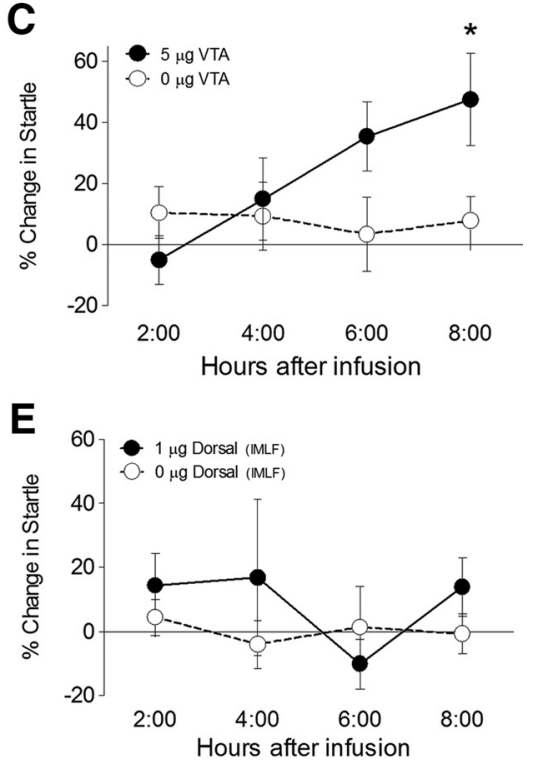

Figure 2. Startle time course during spontaneous withdrawal from intra-VTA morphine infusion. $\boldsymbol{A}$, Timeline of experimental test day for experiment 1. B, Startle was significantly potentiated $4 \mathrm{~h}$ after infusion in the $1 \mu \mathrm{g}$ group vs the $0 \mu \mathrm{g}$ group. C, Startle was significantly potentiated $8 \mathrm{~h}$ after infusion in the $5 \mu \mathrm{g}$ group vs $0 \mu \mathrm{g}$ group. $\boldsymbol{D}$, Animals with misplaced cannulae, located anterior to the VTA in the $L H$, failed to show significant startle potentiation at any time point. For purposes of comparison, the same $0 \mu \mathrm{g}$ control group is presented in panels $\boldsymbol{B}-\boldsymbol{D}$. $\boldsymbol{E}$, Animals with cannulae aimed $1 \mathrm{~mm}$ dorsal to the VTA, located in the IMLF, failed to show significant startle potentiation at any time point. ${ }^{*} p<0.05$ compared with the $0 \mu \mathrm{g}$ group at that time point. Error bars represent SEM in this and all subsequent figures.

A

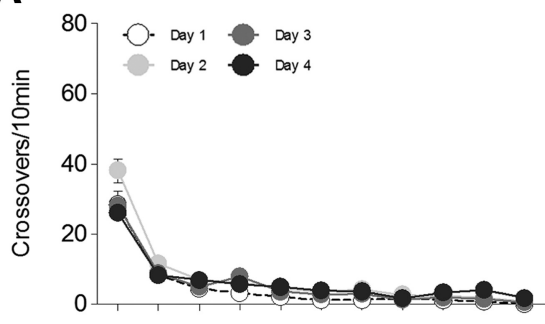

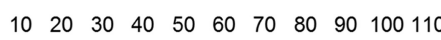

Minutes after $0 \mu \mathrm{g}$ morphine

C

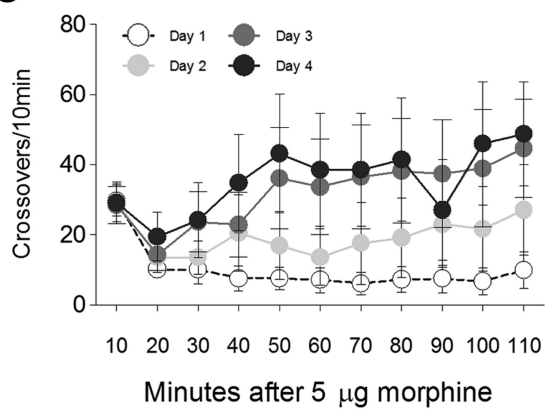

B

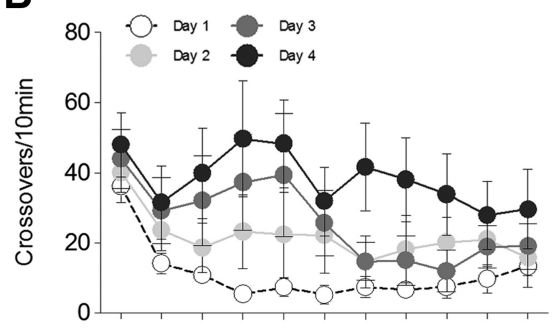

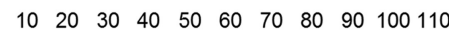

Minutes after $1 \mu \mathrm{g}$ morphine

D

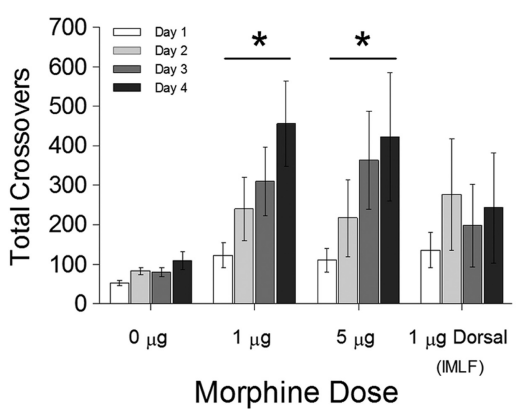

Figure 3. Locomotor activity following intra-VTA morphine infusion. $\boldsymbol{A}-\boldsymbol{C}$, Time course of activity across $4 \mathrm{~d}$ of testing for the 0 $\mu \mathrm{g}$ group $(\boldsymbol{A}), 1 \mu \mathrm{g}$ group $(\boldsymbol{B})$, and $5 \mu \mathrm{g}$ group (C). D. Total locomotor activity across $4 \mathrm{~d}$ of testing. Activity in the 1 and $5 \mu \mathrm{g}$ morphine groups significantly increased over days, as evidenced by significant linear trends in both groups $\left({ }^{*} p<0.05\right)$. No significant effects were found in the $0 \mu \mathrm{g}$ or dorsal control groups.

(data not shown). In each experiment, we first conducted one-way ANOVA to verify similar baseline startle amplitude between experimental groups; there were no differences in baseline startle between groups in any experiment $(\mathrm{Ta}-$ ble 1 and data not shown). Changes in startle after morphine administration were calculated as the percentage change from baseline on the same day (Harris and Gewirtz, 2004).

Data from experiment 1 were analyzed using factorial ANOVA, with repeated measures on within-subject factors. For main effects or interactions involving repeated measures, the Huynh-Feldt correction was applied to control for violations of the sphericity assumption. Between-subjects effects were further analyzed with one-way ANOVA. Planned comparisons (paired $t$ tests or polynomial trend analysis, as appropriate) were used to test the within-subjects effects of intra-VTA morphine and apomorphine on withdrawal-potentiated startle in experiments 2,3 , and 4 . All statistical analysis was conducted using SPSS (version 17.0) with a type I error rate of $\alpha=0.05$ (two-tailed).

\section{Results}

\section{Experiment 1: intra-VTA} morphine infusion

To test whether the VTA is involved in the induction of anxiety following acute opiate exposure, we microinfused morphine sulfate $(0,1$, or $5 \mu \mathrm{g}$ per side) through chronically indwelling cannulae aimed bilaterally at the VTA (Fig. 1A). Startle responding was measured $2,4,6$, or $8 \mathrm{~h}$ after the infusion over 4 test days (Fig. $2 A$ ). A significant main effect of time $\left(F_{(3,126)}=\right.$ $3.555, p=0.016)$ and a significant time $\times$ group interaction $\left(F_{(6,126)}=3.194, p=\right.$ 0.006 ) were observed. Compared with the $0 \mu \mathrm{g}$ group at the same time point, significant potentiation of the startle reflex was observed only in the $1 \mu \mathrm{g}$ group $4 \mathrm{~h}$ after infusion $\left(F_{(1,30)}=4.402, p=0.045\right)$ and in the $5 \mu$ g group $8 \mathrm{~h}$ after infusion $\left(F_{(1,30)}=\right.$ 6.034, $p=0.020$ ) (Fig. $2 B, C$ ). We also found that the increase in startle at $4 \mathrm{~h}$ escalated in magnitude over the 4 test days in the $1 \mu$ g group (day $1: 22.7 \pm 9.2 \%$; day 2: $35.8 \pm 9.2 \%$; day $3: 43.9 \pm 10.8 \%$; day 4 : $68.8 \pm 11.1 \%)$, resulting in a significant linear effect of day $\left(F_{(1,13)}=8.550, p=\right.$ $0.015)$. This effect was not observed in the $0 \mu$ group $\left(F_{(1,16)}=0.015, p=0.904\right)$. Data from animals with misplaced cannulae $(N=5)$ were run against the $0 \mu$ group in a separate analysis, and no significant effects were observed (Fig. 2D). Analysis of data from animals with cannulae aimed 1 mm dorsal to the VTA (Fig. $1 B$ ) also yielded no significant effects (Fig. $2 E$ ), indicating the effects of VTA morphine infusion are not a consequence of dorsal diffusion to the periaqueductal gray (Bozarth and Wise, 1984).

Analysis of locomotor activity re- 
vealed significant main effects of day $\left(F_{(2.444,102.627)}=10.424\right.$, $p<0.001)$ and group $\left(F_{(2,42)}=3.786, p=0.031\right)$. Sensitization of the locomotor response was observed only in $1 \mu \mathrm{g}$ (linear effect of day: $\left.F_{(1,13)}=11.503, p=0.005\right)$ and $5 \mu \mathrm{g}$ infused animals (linear effect of day: $\left.F_{(1,13)}=5.500, p=0.036\right)($ Fig. $3 A-D)$. Analysis of data from animals with cannulae aimed $1 \mathrm{~mm}$ dorsal to the VTA $(0 \mu \mathrm{g}$ group, data not shown; $1 \mu$ g group, included in Fig. $3 D$ ) revealed no significant effects.

\section{Experiment 2: intra-VTA morphine infusion during withdrawal from systemic morphine}

To test whether the expression of opiate withdrawal-induced anxiety requires a reduction in VTA opiate receptor stimulation, rats were systemically injected with morphine sulfate ( 0 or 10 $\mathrm{mg} / \mathrm{kg}$ ) followed by intra-VTA infusion of morphine $(0$ or $1 \mu \mathrm{g}$ per side) $3 \mathrm{~h}$ later (Fig. $4 A$ ). Therefore, in animals given systemic morphine followed by $1 \mu \mathrm{g}$ of intra-VTA morphine, drug levels would be expected to be reduced in all brain regions except the VTA. These animals showed a significantly lower level of withdrawal-potentiated startle than the $0 \mu$ g group $\left(t_{(11)}=2.33\right.$, $p=0.040$ ) (Fig. $4 B$ ). No significant differences were seen between the two $0 \mathrm{mg} / \mathrm{kg}$ groups $\left(t_{(9)}=1.115, p=0.294\right)$.

\section{Experiment 3: intra-VTA naloxone infusion before intra-VTA morphine}

To verify that the effects of intra-VTA morphine observed in experiment 1 were the result of opiate receptor activation, rats received an intra-VTA infusion of naloxone hydrochloride $(0,3$, or $10 \mu$ g per side) followed by intra-VTA morphine ( 0 or $1 \mu \mathrm{g}$ per side) 20 min later (Fig. 4C). Animals given 3 or $10 \mu \mathrm{g}$ of naloxone before $1 \mu \mathrm{g}$ of morphine had a significantly lower level of withdrawal-potentiated startle than animals given $0 \mu \mathrm{g}$ (linear effect of dose: $F_{(1,23)}=5.635, p=0.027$ ) (Fig. 4D). This effect was not observed in the three groups infused with $0 \mu \mathrm{g}$ morphine $\left(F_{(1,32)}=1.205, p=0.281\right)$.

\section{Experiment 4: apomorphine injection during withdrawal} from systemic morphine

As drug levels spontaneously begin to fall in the VTA after acute opiate exposure, the release of dopamine in target structures also decreases (Acquas and Di Chiara, 1992; Spanagel et al., 1992; Wise et al., 1995; Carboni et al., 2000). To test the hypothesis that the expression of anxiety during opiate withdrawal involves a loss of dopaminergic tone, we systemically injected rats with 0 or 10 $\mathrm{mg} / \mathrm{kg}$ morphine sulfate. Three hours and $50 \mathrm{~min}$ later, the animals received a systemic injection of the dopamine receptor agonist apomorphine hydrochloride $(0,50$, or $100 \mu \mathrm{g} / \mathrm{kg})$, and startle responding was tested $10 \mathrm{~min}$ later (Fig. 4E). Animals given $10 \mathrm{mg} / \mathrm{kg}$ morphine followed by apomorphine showed a significant dose-dependent decrease in potentiated startle (linear effect of dose: $F_{(1,29)}=9.09, p=0.006$ ) (Fig. $4 F)$. This effect was not observed in the $0 \mathrm{mg} / \mathrm{kg}$ groups $\left(F_{(1,29)}=\right.$ 1.453, $p=0.239)$.

\section{Discussion}

Negative affective symptoms, such as anxiety and dysphoria, are a common consequence of withdrawal from drugs of abuse that occur after each drug exposure. They are therefore an intrinsic component of drug taking (Koob and Le Moal, 1997; Baker et al., 2004). The current experiments show that withdrawal-induced anxiety develops following activation of the same neural circuitry that mediates the rewarding aspects of drugs. Specifically, we show that the expression of anxiety during opiate withdrawal

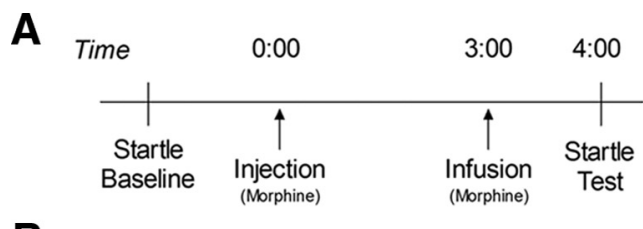

B
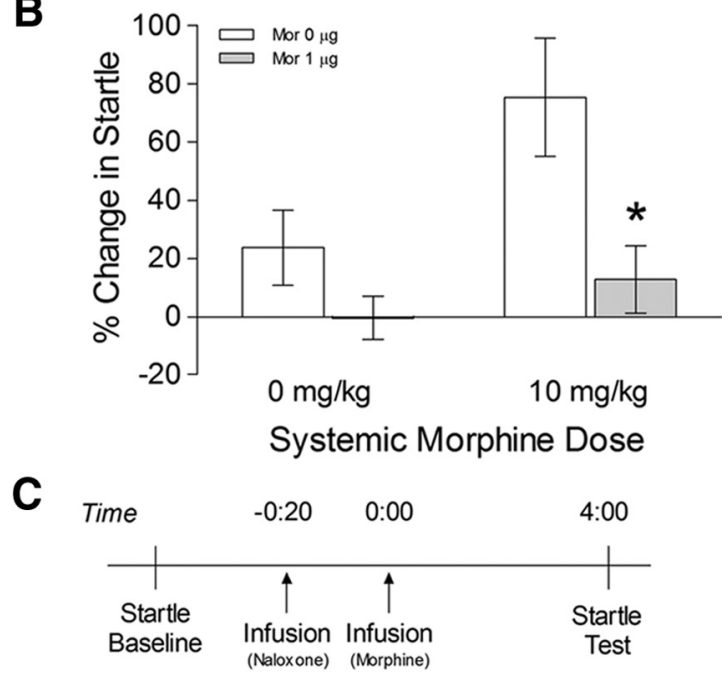

D
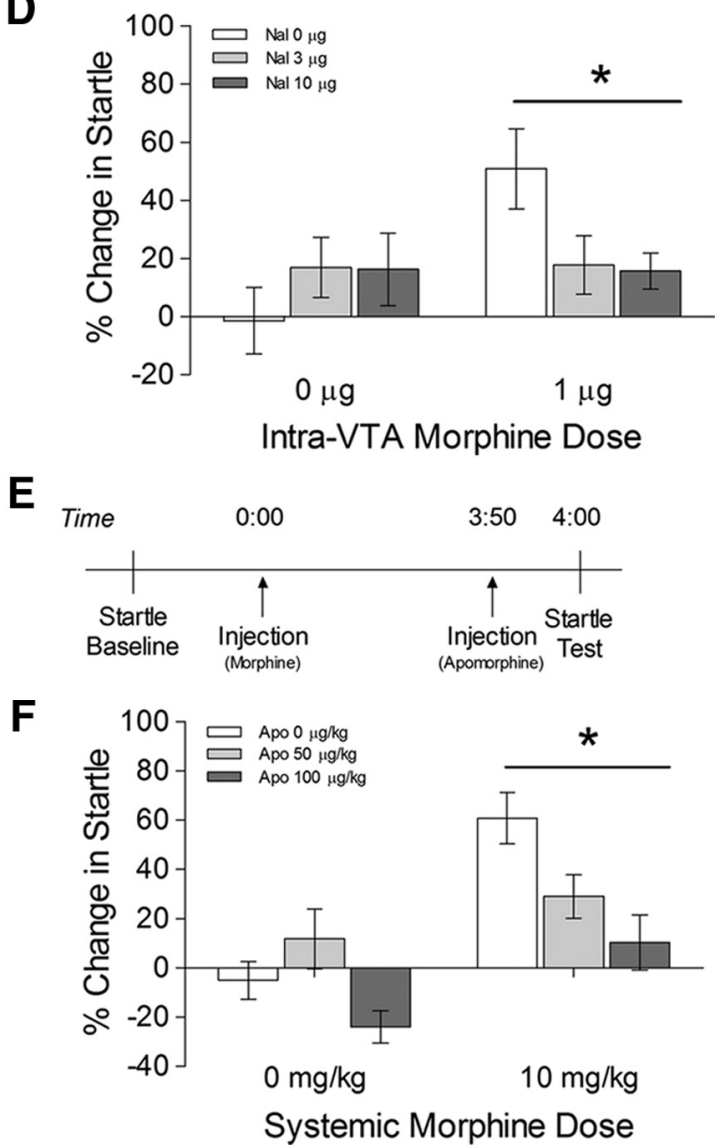

Figure 4. Withdrawal from intra-VTA morphine is dependent on decreased activity at VTA opiate receptors and the dopaminergic system. $\boldsymbol{A}$, Timeline of test day for experiment 2. $\boldsymbol{B}$, Intra-VTA morphine significantly attenuated startle potentiation $\left({ }^{*} p<0.05\right.$ compared with 0 $\mu \mathrm{g}$ group). $\boldsymbol{C}$, Timeline of test day for experiment 3. D, Intra-VTA naloxone significantly attenuated startle potentiation, as evidenced by a significant linear trend $\left({ }^{*} p<0.05\right)$. $\boldsymbol{E}$, Timeline of test day for experiment 4. $\boldsymbol{F}$, Startle potentiation in the morphine group decreased with apomorphine dose, as evidenced by a significant linear trend $\left({ }^{*} p<0.05\right)$. 
results from a drop in activity at VTA opiate receptors and the corresponding loss of dopaminergic tone in terminal fields. Direct microinfusion of morphine into the VTA produces startle potentiation $4 \mathrm{~h}$ later, a time course that is remarkably similar to our previously published studies with systemic opiate administration (Harris and Gewirtz, 2004; Rothwell et al., 2009). This response is specific to the VTA and occurs at a longer latency following administration of a higher dose of morphine, supporting the conclusion that our behavioral measure is a withdrawal effect, and not merely a side effect of morphine exposure. Both potentiated startle and locomotor activity increased in magnitude over repeated testing, further suggesting that they rely on shared mechanisms (Rothwell et al., 2010). Finally, startle potentiation $4 \mathrm{~h}$ after systemic opiate exposure is alleviated by a second intra-VTA microinfusion of morphine, demonstrating that a reduction in activity at VTA opiate receptors is necessary for the expression of withdrawal.

These data offer strong and direct support for opponent process theory, which posits that positive motivational stimuli activate two emotional processes: an initial rewarding process and a secondary negative withdrawal process that is dependent on the first and grows over time (Solomon and Corbit, 1974; Koob and Bloom, 1988). In the case of opiate drugs, the former process is dependent on VTA opiate receptors and the subsequent release of dopamine in target structures (Bozarth and Wise, 1984; Olmstead and Franklin, 1997; Fenu et al., 2006). As predicted by opponent process theory, our data demonstrate that anxiety-like behavior during opiate withdrawal is initiated by prior activation of the same circuitry and escalates over repeated exposures.

We also find the degree of psychomotor activation produced by VTA morphine infusion is enhanced with repeated exposure, consistent with previous reports (Vezina and Stewart, 1984; Shaham et al., 1995) and other evidence that intermittent drug exposure causes sensitization of the mesolimbic dopamine system (Robinson and Berridge, 2003). In contrast, the original opponent process theory suggests that the responsiveness of the reward system should diminish over repeated drug exposures (Solomon and Corbit, 1974). However, the initial manifestations of acute morphine withdrawal are not observed until after peak activation of the mesolimbic dopamine system by VTA morphine infusion (Broekkamp et al., 1979; Leone et al., 1991). This delay provides a window of opportunity for expression of sensitization before the opponent process emerges. The subsequent expression of anxiety likely coincides with reduced activation of the mesolimbic dopamine system (Acquas and Di Chiara, 1992; Rossetti et al., 1992; Diana et al., 1995, 1999; Georges and Aston-Jones, 2003; Georges et al., 2006), which contributes to negative emotional states (Stinus et al., 1990; Nestler and Carlezon, 2006; Liu et al., 2008). This idea is further supported by our data demonstrating that systemic apomorphine attenuates withdrawalpotentiated startle as well as other evidence that manipulation of dopaminergic signaling attenuates signs of opiate withdrawal (Harris and Aston-Jones, 1994; Bechara et al., 1995; Rodriguez-Arias et al., 1999; Laviolette et al., 2002; Chartoff et al., 2006; but, see Caillé et al., 2003).

In addition to changes within the mesolimbic dopamine system, the development of an opponent process during drug withdrawal involves "between-systems" adaptations in structures responsible for the expression of negative affect (Koob and Bloom, 1988; Stinus et al., 1990; Harris et al., 2006; Smith and Aston-Jones, 2008). Our data suggest that activation of the mesolimbic dopamine system may be the first step in the recruitment of between-systems adaptations that produce anxiety. Transient release of dopamine in portions of the extended amygdala (Acquas and Di Chiara, 1992; Spanagel et al., 1992; Wise et al., 1995; Carboni et al., 2000) may trigger increased release of corticotropin-releasing factor and norepinephrine (Guiard et al., 2008; Kash et al., 2008). Additionally, dopaminergic regulation of corticotropin-releasing factor synthesis in the extended amygdala (Smiałowska et al., 1999; Day et al., 2002; Stewart et al., 2008) could contribute to allostatic changes that mediate increased withdrawal severity following repeated opiate exposure. Further research will be necessary to directly determine whether this dopaminergic link between the VTA and the extended amygdala is in fact involved in anxiety following acute opiate exposure. In addition to the extended amygdala, the tegmental pedunculopontine nucleus (PPTg) is important in the development of an opponent process following opiate exposure (Vargas-Perez et al., 2007, 2009). The PPTg sends excitatory glutamatergic and cholinergic inputs to dopamine cells (Oakman et al., 1995; Geisler et al., 2007), and its role in opiate reward and withdrawal may therefore be mediated by its ability to drive VTA dopaminergic activity (Pan and Hyland, 2005).

In contrast to the current findings, intra-VTA morphine infusion does not produce physical signs of dependence (Bozarth and Wise, 1984). This is not surprising given the abundant evidence that physical and emotional aspects of withdrawal are mediated by distinct mechanisms (Koob et al., 1992; Higgins and Sellers, 1994). It will be important for future work to determine whether other emotional facets of the withdrawal syndrome, such as anhedonia and dysphoria, involve the same mechanisms described here. It will also be interesting to see whether similar increases in anxiety-like behavior are seen with models of anxiety that involve a suppression instead of a potentiation of behavior. Such an outcome is likely given that potentiated startle correlates highly with freezing behavior, another common measure of anxiety in rodents (Leaton and Borszcz, 1985).

Taken as a whole, our findings demonstrate that the induction of a negative affective opponent process following acute opiate exposure is dependent on a reduction in activation of the neural circuitry responsible for the rewarding effects of the drug. Since the negative emotional component of withdrawal is thought to play a strong motivational role in drug taking behavior (Koob and Le Moal, 1997; Baker et al., 2004), our findings may be particularly relevant to the study of the development and escalating severity of drug dependence.

\section{References}

Acquas E, Di Chiara G (1992) Depression of mesolimbic dopamine transmission and sensitization to morphine during opiate abstinence. J Neurochem 58:1620-1625.

Baker TB, Piper ME, McCarthy DE, Majeskie MR, Fiore MC (2004) Addiction motivation reformulated: an affective processing model of negative reinforcement. Psychol Rev 111:33-51.

Bechara A, Nader K, van der Kooy D (1995) Neurobiology of withdrawal motivation: evidence for two separate aversive effects produced in morphine-naïve vs. morphine-dependent rats by both naloxone and spontaneous withdrawal. Behav Neurosci 109:91-105.

Bergstrom DA, Bromley SD, Walters JR (1982) Apomorphine increases the activity of rat globus pallidus neurons. Brain Res 238:266-271.

Bozarth MA, Wise RA (1984) Anatomically distinct opiate receptor fields mediate reward and physical dependence. Science 224:516-517.

Broekkamp CL, Phillips AG (1979) Facilitation of self-stimulation behavior 
following intracerebral microinjections of opioids into the ventral tegmental area. Pharmacol Biochem Behav 11:289-295.

Cabral A, Ruggiero RN, Nobre MJ, Brandão ML, Castilho VM (2009) GABA and opioid mechanisms of the central amygdala underlie the withdrawal-potentiated startle from acute morphine. Prog Neuropsychopharmacol Biol Psychiatry 33:334-344.

Caillé S, Rodriguez-Arias M, Minarro J, Espejo EF, Cador M, Stinus L (2003) Changes in dopaminergic neurotransmission do not alter somatic or motivational opiate withdrawal-induced symptoms in rats. Behav Neurosci 117:995-1005.

Carboni E, Silvagni A, Rolando MT, Di Chiara G (2000) Stimulation of in vivo dopamine transmission in the bed nucleus of the stria terminalis by reinforcing drugs. J Neurosci 20: RC102.

Carlson JH, Bergstrom DA, Walters JR (1987) Stimulation of both D1 and D2 dopamine receptors appears necessary for full expression of postsynaptic effects of dopamine agonists: a neurophysiological study. Brain Res 400:205-218.

Chartoff EH, Mague SD, Barhight MF, Smith AM, Carlezon WA Jr (2006) Behavioral and molecular effects of dopamine D1 receptor stimulation during naloxone-precipitated morphine withdrawal. J Neurosci 26: $6450-6547$.

Davis M, Walker DL, Miles L, Grillon C (2010) Phasic vs. sustained fear in rats and humans: role of the extended amygdala in fear vs. anxiety. Neuropsychopharmacology 35:105-135.

Day HE, Vittoz NM, Oates MM, Badiani A, Watson SJ Jr, Robinson TE, Akil $\mathrm{H}$ (2002) A 6-hydroxydopamine lesion of the mesostriatal dopamine system decreases the expression of corticotropin releasing hormone and neurotensin mRNAs in the amygdala and bed nucleus of the stria terminalis. Brain Res 945:151-159.

de Olmos JS, Heimer L (1999) The concepts of the ventral striatopallidal system and extended amygdala. Ann NY Acad Sci 877:1-32.

Diana M, Pistis M, Muntoni A, Gessa G (1995) Profound decrease of mesolimbic dopaminergic neuronal activity in morphine withdrawn rats. J Pharmacol Exp Ther 272:781-785.

Diana M, Muntoni AL, Pistis M, Melis M, Gessa GL (1999) Lasting reduction in mesolimbic dopamine neuronal activity after morphine withdrawal. Eur J Neurosci 11:1037-1041.

Fallon JH, Koziell DA, Moore RY (1978) Catacholamine innervation of the basal forebrain: II. Amygdala, suprarhinal cortex, and entorhinal cortex. J Comp Neur 180:509-532.

Fenu S, Spina L, Rivas E, Logoni R, Di Chiara G (2006) Morphineconditioned single trial place preference: role of nucleus accumbens shell dopamine receptors in acquisition, but not expression. Psychopharmacology (Berl) 187:143-153.

Frenois F, Cador M, Caillé S, Stinus L, Le Moine C (2002) Neural correlates of the motivational and somatic components of naloxone-precipitated morphine withdrawal. Eur J Neurosci 16:1377-1389.

Geisler S, Derst C, Veh RW, Zahm DS (2007) Glutamatergic afferents of the ventral tegmental area in the rat. J Neurosci 27:5730-5743.

Georges F, Aston-Jones G (2003) Prolonged activation of mesolimbic dopamine neurons by morphine withdrawal following clonidine: participation of imidazoline and norepinephrine receptors. Neuropsychopharmacology 28:1140-1149.

Georges F, Le Moine C, Aston-Jones G (2006) No effect of morphine on ventral tegmental dopamine neurons during withdrawal. J Neurosci 26:5720-5726.

Guiard BP, El Mansari M, Blier P (2008) Cross-talk between dopaminergic and noradrenergic systems in the rat ventral tegmental area, locus ceruleus, and dorsal hippocampus. Mol Pharmacol 74:1463-1475.

Gutman AR, Yang Y, Ressler KJ, Davis M (2008) The role of neuropeptide Y in the expression and extinction of conditioned fear. J Neurosci 28:12682-12690.

Harris AC, Gewirtz JC (2004) Elevated startle during withdrawal from acute morphine: a model of opiate withdrawal and anxiety. Psychopharmacology (Berl) 171:140-147.

Harris AC, Atkinson DM, Aase DM, Gewirtz JC (2006) Double dissociation in the neural substrates of acute opiate dependence as measured by withdrawal-potentiated startle. Neuroscience 139:1201-1210.

Harris GC, Aston-Jones G (1994) Involvement of D2 dopamine receptors in the nucleus accumbens in the opiate withdrawal syndrome. Nature 371:155-157.

Hasue RH, Shammah-Lagnado SJ (2002) Origin of the dopaminergic inner- vation of the central extended amygdala and accumbens shell: a retrograde and immunohistochemical study in the rat. J Comp Neurol 454: $15-33$.

Herman JP, Guillonneau D, Dantzer R, Scatton B, Semerdjian-Rouquier L, Le Moal M (1982) Differential effects of inescapable footshocks and of stimuli previously paired with inescapable footshocks on dopamine turnover in cortical and limbic areas of the rat. Life Sciences 30:2207-2214

Higgins GA, Sellers EM (1994) Antagonist-precipitated opioid withdrawal in rats: evidence for dissociations between physical and motivational signs. Pharmacol Biochem Behav 48:1-8.

Johnson SW, North RA (1992) Opioids excite dopamine neurons by hyperpolarization of local interneurons. J Neurosci 12:483-488.

Kalinichev M, Holtzman SG (2003) Changes in urination/defecation, auditory startle response, and startle-induced vocalizations in rats undergoing morphine withdrawal: similarities and differences between acute and chronic dependence. J Pharmacol Exp Ther 304:603-609.

Kash TL, Nobis WP, Matthews RT, Winder DG (2008) Dopamine enhances fast excitatory synaptic transmission in the extended amygdala by a CRF-R1 dependent process. J Neurosci 28:13856-13865.

Koob GF, Bloom FE (1988) Cellular and molecular mechanisms of drug dependence. Science 242:715-723.

Koob GF, Le Moal M (1997) Drug abuse: hedonic homeostatic dysregulation. Science 278:52-58.

Koob GF, Maldonado R, Stinus L (1992) Neural substrates of opiate withdrawal. Trends Neurosci 15:186-191.

Laviolette SR, Nader K, van der Kooy D (2002) Motivational state determines the functional role of the mesolimbic dopamine system in the mediation of opiate reward processes. Behav Brain Res 129:17-29.

Leaton RN, Borszcz GS (1985) Potentiated startle: its relation to freezing and shock intensity in rats. J Exp Psychol 11:421-428.

Leone P, Pocock D, Wise RA (1991) Morphine-dopamine interaction: ventral tegmental morphine increases nucleus accumbens dopamine release. Pharmacol Biochem Behav 39:469-472.

Liu ZH, Shin R, Ikemoto S (2008) Dual role of medial A10 dopamine neurons in affective encoding. Neuropsychopharmacology 33:3010 3020 .

Maldonado R, Stinus L, Gold LH, Koob GF (1992) Role of different brain structures in the expression of the physical morphine withdrawal syndrome. J Pharmacol Exp Ther 261:669-677.

Meloni EG, Gerety LP, Knoll AT, Cohen BM, Carlezon WA Jr (2006) Behavioral and anatomical interactions between dopamine and corticotropinreleasing factor in the rat. J Neurosci 26:3855-3863.

Nakagawa T, Yamamoto R, Fujio M, Suzuki Y, Minami M, Satoh M, Kaneko S (2005) Involvement of the bed nucleus of the stria terminalis activated by the central nucleus of the amygdala in the negative affective component of morphine withdrawal in rats. Neuroscience 134:9-19.

Nestler EJ, Carlezon WA Jr (2006) The mesolimbic dopamine reward circuit in depression. Biol Psychiat 59:1151-1159.

Oakman SA, Faris PL, Kerr PE, Cozzari C, Hartman BK (1995) Distribution of pontomesencephalic cholinergic neurons projecting to substantia nigra differs significantly from those projecting to ventral tegmental area. J Neurosci 15:5859-5869.

Olmstead MC, Franklin KB (1997) The development of a conditioned place preference to morphine: effects of microinjections into various CNS sites. Behav Neurosci 111:1324-1334.

Pan WX, Hyland BI (2005) Pedunculopontine tegmental nucleus controls conditioned responses of midbrain dopamine neurons in behaving rats. J Neurosci 25:4725-4732.

Pezze MA, Feldon J (2004) Mesolimbic dopamine pathways in fear conditioning. Prog Neurobiol 74:301-320.

Robinson TE, Berridge KC (2003) Addiction. Annu Rev Psychol 54:25-53.

Rodríguez-Arias M, Pinazo J, Miñarro J, Stinus L (1999) Effects of SCH 23390, raclopride, and haloperidol on morphine withdrawal-induced aggression in male mice. Pharmacol Biochem Behav 64:123-130.

Rosenkranz JA, Grace AA (1999) Modulation of basolateral amygdala neuronal firing and afferent drive by dopamine receptor activation in vivo. J Neurosci 19:11027-11039.

Rossetti ZL, Hmaidan Y, Gessa GL (1992) Marked inhibition of mesolimbic dopamine release: a common feature of ethanol, morphine, cocaine, and amphetamine abstinence in rats. Eur J Pharmacol 221:227-234.

Rothwell PE, Thomas MJ, Gewirtz JC (2009) Distinct profiles of anxiety and 
dysphoria during spontaneous withdrawal from acute morphine exposure. Neuropsychopharmacology 34:2285-2295.

Rothwell PE, Gewirtz JC, Thomas MJ (2010) Episodic withdrawal promotes psychomotor sensitization to morphine. Neuropsychopharmacology 35:2579-2589.

Shaham Y, Kelsey JE, Stewart J (1995) Temporal factors in the effect of restraint stress on morphine-induced behavioral sensitization in the rat. Psychopharmacology (Berl) 117:102-109.

Smiałowska M, Bajkowska M, Prezewł ocka B, Maj M, Turchan J, Przewł ocki $\mathrm{R}$ (1999) Effect of 6-hydroxydopamine on neuropeptide $\mathrm{Y}$ and corticotropin-releasing factor expression in rat amygdala. Neuroscience 94:1125-1132.

Smith RJ, Aston-Jones G (2008) Noradrenergic transmission in the extended amygdala: role in increased drug-seeking and relapse during protracted drug abstinence. Brain Struct Funct 213:43-61.

Solomon RL, Corbit JD (1974) An opponent process theory of motivation. Psychol Rev 81:119-145.

Spanagel R, Herz A, Shippenberg TS (1992) Opposing tonically active endogenous opioid systems modulate the mesolimbic dopaminergic pathway. Proc Natl Acad Sci U S A 89:2046-2050.

Stewart J, Horton C, Robinson B, Amir S (2008) Unilateral loss of dopa- minergic innervation suppresses the expression of CRF-IR in the ipsilateral oval nucleus of the bed nucleus of the stria terminalis and central nucleus of the amygdala in the rat. Soc Neurosci Abstr 34:767.21.

Stinus L, Le Moal M, Koob GF (1990) Nucleus accumbens and amygdala are possible substrates for the aversive stimulus effects of opiate withdrawal. Neuroscience 37:767-773.

Vargas-Perez H, Ting-A-Kee RA, Heinmiller A, Sturgess JE, van der Kooy D (2007) A test of the opponent process theory of motivation using lesions that selectively block morphine reward. Eur J Neurosci 25:3713-3718.

Vargas-Perez H, Ting-A-Kee R, van der Kooy D (2009) Different neural systems mediate morphine reward and its spontaneous withdrawal aversion. Eur J Neurosci 29:2029-2034.

Vezina P, Stewart J (1984) Conditioned and place-specific sensitization of increases in activity induced by morphine in the VTA. Pharmacol Biochem Behav 20:925-934.

Wise RA, Leone P, Rivest R, Leeb K (1995) Elevations of nucleus accumbens dopamine and DOPAC levels during intravenous heroin selfadministration. Synapse 21:140-148. 